\title{
Biomolecular Mimic Circuit for an Allosterically Regulated Enzyme of Pyrimidine Biosynthetic Pathway
}

R.Vinoth ${ }^{1}$ and S. Balaji ${ }^{* *}$

${ }^{1}$ Department of Electronics and Communication, Manipal Institute of Technology, Manipal University, Manipal -576104

${ }^{2}$ Department of Biotechnology, Manipal Institute of Technology, Manipal University, Manipal -576104

\begin{abstract}
A general type of molecular level metabolic control that is common to all living organisms is the feedback inhibition, wherein an increase in the product of a metabolic pathway regulates an enzyme upstream in the cascade by binding to it and decreasing enzyme activity. The de novo pyrimidine biosynthetic pathway provides a specific example for the feedback inhibition. Aspartate transcarbamoylase (ATCase) catalyzes the first step in the biosynthesis of pyrimidines and one of the best understood allosteric enzymes. The structure of ATCase is roughly triangular in shape, similar to the symbol of an op-amp IC. Since most of the enzymatic properties were analogous to the properties of IC, this inspired us to mimic the enzyme (EC 2.1.3.2) with an IC (PIN $\mu A 741 C N)$ in our circuit design. The Michaelis-Menten model, Lineweaver-Burk equation and the equation for the non-inverting amplifier were theoretically related and used for our model. As a result, an electronic feedback circuit was designed and tested. The biomolecular mimic circuit will develop a new level of understanding of the metabolic complexity in the cell.
\end{abstract}

Keywords: Biomolecular mimetics; Biomimetic circuit; ATCase; Feedback; Op-amp IC

\section{Introduction}

The metabolic and physiological processes of living cells are regulated in a variety of ways. In general, regulatory biochemical mechanisms respond to change by damping the effect (of course, there are situations where amplification occurs). In each biochemical pathway there are one or more enzymatic "nanomachines" whose catalytic activity can be modulated in response to cellular needs. This gives the cell very great control over metabolism and utilization of energy resources [1]. Such regulatory enzymes usually catalyze the first unique (or "committed") step in a pathway. It should be noted that the control of metabolic processes is complex. Cells use allosteric regulation to respond effectively to certain changes in the intracellular conditions. The binding of an effector to an allosteric enzyme can either increase or decrease the binding affinity of substrate to that enzyme.

The de novo pyrimidine biosynthetic pathway provides a specific example of feedback inhibition. There are about seven different enzymatic nanomachines on the molecular assembly line [2]. Escherichia coli aspartate transcarbamoylase (ATCase, EC 2.1.3.2) is a choice object of investigation on regulatory mechanisms, cooperativity and intramolecular signal transmission. This reaction proceeds through an ordered mechanism in which carbamoyl phosphate binds first, inducing a local conformational change of ATCase which, then, allows the binding of the second substrate aspartate $[3,4]$ to generate $\mathrm{N}$-carbamoyl-L-aspartate with the release of inorganic phosphate [5]. On a mechanistic level, inhibition of a key enzymatic nanomachine (ATCase) on the assembly line results by a feedback mechanism, the physical association of the end product (Cytidine triphosphate, CTP) with the first enzyme in its "fabrication process". On the contrary it is stimulated by Adenosine triphosphate (ATP). This antagonism contributes to ensure the intracellular balance of purine and pyrimidine nucleotides for DNA synthesis in the cell [6]. The bacterial ATCase controls the rate of pyrimidine metabolism by homotropic and heterotropic interactions [7]. Substrates bind to the enzyme and induce a tertiary domain closure that triggers a quaternary conformational change resulting in the observed homotropic cooperativity [8]. CTP and ATP are the end products of the pyrimidine and purine nucleotide biosynthetic pathways, respectively, can inhibit/activate the enzyme heterotropically [9-11]. ATCase molecule consists of six catalytic subunits and six regulatory subunits $\mathrm{C}_{6} \mathrm{R}_{6}$. The catalytic subunits bind the substrate molecules, and the allosteric subunits bind the allosteric inhibitor, CTP. The entire ATCase molecule exists in two conformations, active and inactive. These forms are referred as the $\mathrm{T}$ (for taut/tense) state and the $\mathrm{R}$ (for relaxed) state, respectively [12]. The $\mathrm{T}$ state has lower affinity for substrates and, hence, lower catalytic activity than does the $\mathrm{R}$ state. In the presence of any fixed concentration of aspartate and carbamoyl phosphate, the enzyme exists in equilibrium between the $\mathrm{T}$ and the $\mathrm{R}$ forms. When CTP is not bound to the regulatory subunits, the enzyme is maximally active. As CTP accumulates and binds to the regulatory subunits, they shift the equilibrium toward the $\mathrm{T}$ state, decreasing the net enzyme activity and reducing the rate of $\mathrm{N}$-carbamoylaspartate generation [13]. This mechanism for allosteric regulation is referred to as the concerted mechanism because the change in the enzyme is "all or none". An increase in substrate concentration favors the entire enzyme converted from $\mathrm{T}$ state to the $\mathrm{R}$, affecting all of the catalytic sites equally $[12,14]$. The main aim of our work is to mimic this biochemical feedback mechanism and design an equivalent electronic circuit to develop a new level of understanding of the metabolic complexity of the cell.

\section{Materials and Methods}

\section{Aspartate transcarbamoylase (ATCase)}

ATCase is the key enzyme (EC 2.1.3.2) catalyzes the first step in the

*Corresponding author: S. Balaji, Department of Biotechnology, Manipal Institute of Technology, Manipal University, Manipal-576104, Udupi (Dt.), Karnataka, India, Tel: +9109036260732; E-mail: blast_balaji@rediffmail.com, s.balaji@manipal.edu

Received December 17, 2011; Accepted January 18, 2012; Published January 22, 2012

Citation: Vinoth R, Balaji S (2012) Biomolecular Mimic Circuit for an Allosterically Regulated Enzyme of Pyrimidine Biosynthetic Pathway. J Biosens Bioelectron 3:117. doi:10.4172/2155-6210.1000117

Copyright: (C) 2012 Vinoth R, et al. This is an open-access article distributed under the terms of the Creative Commons Attribution License, which permits unrestricted use, distribution, and reproduction in any medium, provided the original author and source are credited. 
pyrimidine biosynthetic pathway. ATCase is a multi-subunit protein complex composed of 12 integrated chains or subunits $(300 \mathrm{kDa}$ in total) and the overall structure is roughly triangular in shape that is similar to the symbol of an operational amplifier (op-amp) integrated circuit (IC) which is composed of transistors rather than subunits [15]. This inspired us to mimic the enzyme with an IC (PIN $\mu$ A741CN) in our circuit design (Figure 1). The operating temperature of this IC is between -55 and $+125^{\circ} \mathrm{C}[16]$.

\section{The theoretical model}

Two theoretical models that attempt to explain the behavior of allosteric enzymes are the concerted model and the sequential model. The former was introduced by Monod, Wyman and Changeux, referred as the MWC hypothesis [17] and the latter was introduced by Koshland, Nemethy and Filmer and is often called the KNF hypothesis [18]. Since the former model accounts only for positive cooperativity, it was mimicked by using non-Inverting amplifier (i.e., the input was connected to the non-inverting pin (+) and the inverting pin (-) of the amplifier was grounded). In the former model, it is assumed that the enzyme exists in only two states: $\mathrm{T}$ (aut) and $\mathrm{R}$ (elaxed) with different $\mathrm{K}_{\mathrm{Ms}}$. Similarly, the op-amp has two regions i.e., linear and saturation regions. Hence, different resistors were used to indicate different $\mathrm{K}_{\mathrm{Ms}}$.

Although Michaelis-Menten (MM) model [19] was not applicable to allosteric enzymes, the series of reactions were hypothesized by using a similar substrate-reaction model i.e., an enzyme (E) combines with a substrate (S) to form an enzyme-substrate (ES) complex, which can proceed to form a product $(\mathrm{P})$. Only the forward reaction of $\mathrm{MM}$ model is mimicked to make our theoretical model. In which, ' $\mathrm{E}$ ' is the gain (A), obtained using different resistors, ' $\mathrm{S}$ ' is the input voltage $\left(V_{\mathrm{i}}\right)$, 'ES' is the product of gain and input voltages $\left(\mathrm{A} V_{\mathrm{i}}\right)$ and ' $\mathrm{P}$ ' is the output voltage $\left(V_{0}\right)$ obtained by using superposition theorem [20]. $\mathrm{k} 1$ and $\mathrm{k} 2$ are the rate constants for the individual steps differentiated with resistor values $\left(\mathrm{R}_{1} \& \mathrm{R}_{2}\right)$.

$$
E+S \stackrel{k 1}{\longrightarrow} E S \stackrel{k 2}{\longrightarrow} E+P
$$

As enzyme-catalysed reactions are saturable (similar to op-amp IC), their rate of catalysis does not show a linear response to increasing

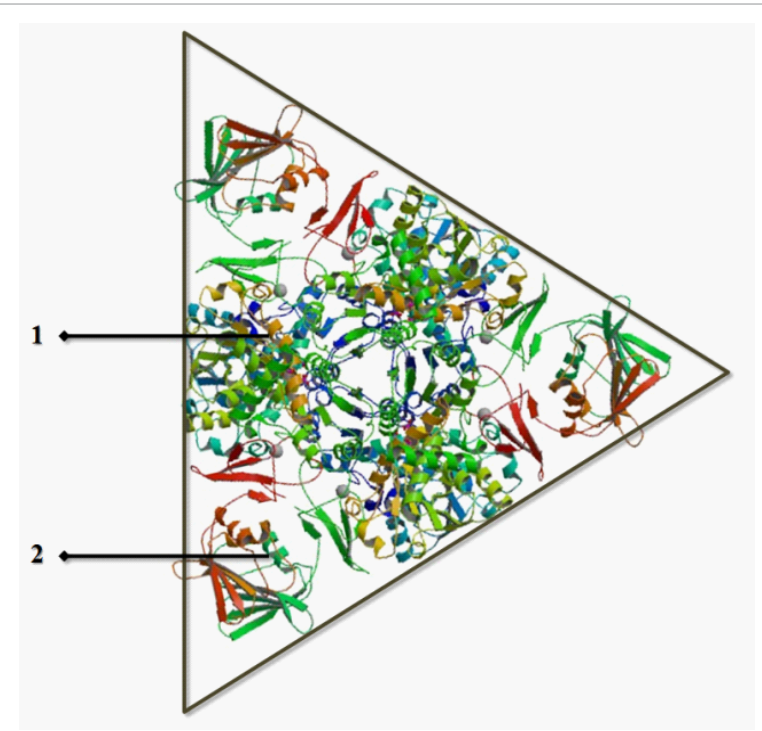

Figure 1: ATCase crystal structure (2.85 $\AA$ ), the catalytic component comprising three subunits is labeled as 1 and the regulatory component comprising two subunits is labeled as 2 . substrate. If the substrate concentration [S], gets higher, the enzyme becomes saturated with substrate and the rate reaches $V_{\max }$, (the enzyme's maximum rate) which is approximately equals to op-amp IC supply voltage $\left(V_{c c}\right)$. The rate $\left(V_{0}\right)$ of formation of product is given by the MM equation:

$$
V_{0}=\frac{V_{\max }[S]}{K_{M}+[S]}
$$

in which $V_{\max }$ is the reaction rate when the enzyme is fully saturated with substrate and $K_{M}$, the Michaelis constant, is the substrate concentration at which the reaction rate is half maximal.

This equation Equation (2) is the basis for most single-substrate enzyme kinetics. A more illustrative version of the MM equation is the Lineweaver-Burk (LB) equation [21]. Therefore, linearization of the MM equation, the LB equation was used. This is produced by taking the reciprocal of both sides of the MM equation Equation 2. Hence,

$$
\frac{1}{V_{0}}=\frac{1}{V_{\max }}+\frac{K_{M}}{V_{\max }} \times \frac{1}{[S]}
$$

Similarly, the equation for the non-inverting amplifier (Figure 2) is given as

$$
V_{0}=V_{i}\left[1+\frac{R_{f}}{R_{1}}\right]
$$

The same equation (4) can be rearranged as

$$
\begin{aligned}
& \frac{1}{V_{i}}=\frac{1}{V_{0}}\left[1+\frac{R_{f}}{R_{1}}\right] \\
& \frac{1}{V_{i}}=\frac{1}{V_{0}}+\frac{R_{f}}{V_{0}} \times \frac{1}{R_{1}}
\end{aligned}
$$

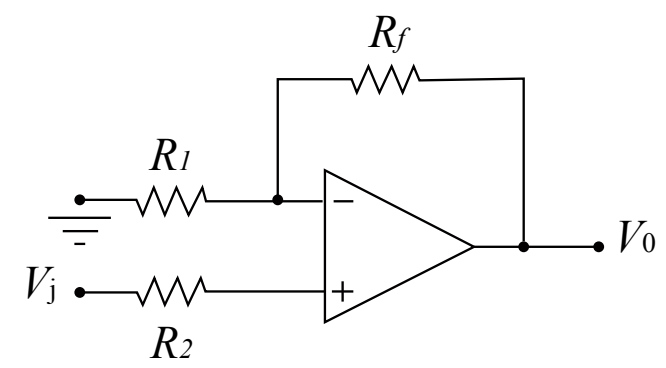

Figure 2: Basic circuit of the non-inverting amplifier.

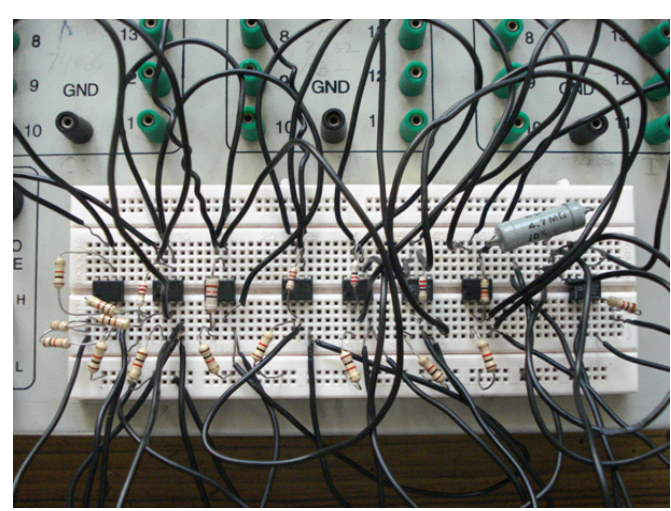

Figure 3: The tested electronic feedback circuit. 
Where $V_{\mathrm{i}}$ is the input voltage. $\mathrm{R}_{1}$ is resistance and $\mathrm{R}_{\mathrm{f}}$ is the feedback resistor which provides feedback voltage. $V_{0}$ is the output voltage. The LB equation Equation (3) and the equation for the non-inverting amplifier Equation (5) were theoretically related and used for our model.

\section{The circuit design}

The electronic circuit model was designed and tested using digital IC trainer bread board (ALS- Advanced Electronic Systems, Bangalore, India) shown in Figure 3. Eight op-amps $(\mu \mathrm{A} 741 \mathrm{CN})$ were used to mimic the enzymatic nanomachines and their regulation of the pyrimidine synthetic pathway. The circuit model consists of three stages; the adder-subtractor, the non-inverting amplifier and the precision clamp, respectively to handle two different situations (refer 2.4).

The adder-substractor: The adder-substractor circuit with unity gain was used in the first stage [20]. The $\mathrm{V}_{1}, \mathrm{~V}_{2}, \mathrm{~V}_{3}$ and $\mathrm{V}_{4}$ are input voltages applied to the adder-subtractor circuit. The input voltages $\mathrm{V}_{1}$ and $V_{2}$ were connected to the inverting pin (No: 2) of the op-amp $\left(A_{1}\right)$ through resistors $R_{1}$ and $R_{2}$ correspondingly. The input voltages $V_{3}$ and $\mathrm{V}_{4}$ were connected to the non-inverting pin (No: 3 ) of the op-amp through resistors $\mathrm{R}_{3}$ and $\mathrm{R}_{4}$ correspondingly. The output is taken from the output pin (No: 6) of the adder-subtractor section is denoted as $\mathrm{V}_{5}$.

Non-inverting amplifier (NIA): There are six non-inverting amplifiers used in this section with gain of 1.022. All the inputs to the non-inverting amplifiers [22,23] were connected to the non-inverting pin (No: 3 ) of the corresponding amplifiers and the inverting pins (No: 2 ) of all amplifiers were grounded. The outputs were taken from the output pins (No: 6 ) of the non-inverting amplifiers. The outputs from first NIA $\left(\mathrm{A}_{2}\right)$ denoted as $\mathrm{V}_{6}$, second NIA $\left(\mathrm{A}_{3}\right)$ denoted as $\mathrm{V}_{7}$, third NIA $\left(A_{4}\right)$ denoted as $V_{8}$, fourth NIA $\left(A_{5}\right)$ denoted as $V_{9}$, fifth NIA $\left(A_{6}\right)$ denoted as $V_{10}$ and sixth NIA $\left(A_{7}\right)$ denoted as $V_{11}$.

Precision clamp: Amplifier $\left(\mathrm{A}_{8}\right)$ was used as precision clamp [24]. The output from sixth NIA $\left(\mathrm{V}_{11}\right)$ was connected to inverting pin (No: 2) of $A 8$ through resistor R. External $V_{\text {ref }}$ voltage is connected to the non-inverting terminal of the precision clamp. Here $\mathrm{V}_{\text {ref }}$ is considered as ATP. A diode was placed in the feedback loop of the precision clamp. The output is taken from cathode of diode (denoted as $\mathrm{V}_{12}$ ).

\section{The circuit working principle}

Initially the input voltage $\mathrm{V}_{1}$ and $\mathrm{V}_{2}$ to adder-subtractor was zero (case 0 ), so that the inverting terminal of adder-subtractor is grounded. Now the input voltage to the non-inverting terminal $\left(\mathrm{V}_{3}\right.$ and $\left.\mathrm{V}_{4}\right)$ is kept at $0.378 \mathrm{~V}$. The DC power supply is used to feed this input voltage [Aplab7711 multioutput DC power supply, (0-30V) / (0-2A) DC, $+15 \mathrm{~V}$, $-15 \mathrm{~V} /(0.5 \mathrm{~A})]$. Digital multimeter (Aplab1004, Aplab Ltd.) was used to measure the DC voltages. below.

The working principles for two different conditions are given

Case 1: If CTP $\left(\mathrm{V}_{11}\right)>\operatorname{ATP}\left(\mathrm{V}_{\text {ref }}\right)$

Case 2: If $\operatorname{ATP}\left(\mathrm{V}_{\text {ref }}\right)>\operatorname{CTP}\left(\mathrm{V}_{11}\right)$

In case 1 , the output from precision clamp $\left(\mathrm{V}_{12}\right)$ serves as inverting inputs $\left(\mathrm{V}_{1}\right.$ and $\left.\mathrm{V}_{2}\right)$ for the adder-subtractor which is connected through wire. The output from this declines gradually. Whereas in the case 2, the inverting inputs are connected through resistor (R"), the output increases gradually.

\section{Results and Discussion}

The de novo pyrimidine biosynthetic pathway was conceptually mimicked with electronic components. As a result, an electronic feedback circuit was designed and tested. The structure of the pacemaker enzyme, ATCase, is roughly triangular in shape which is similar to the symbol of an op-amp IC (Figure 1). This inspired us to mimic the enzyme (EC 2.1.3.2) with an IC (PIN: $\mu \mathrm{A} 741 \mathrm{CN}$ ) in our circuit design. Since most of the enzymatic properties were analogous with the properties of IC, the successive enzymatic nanomachines were also mimicked with op-amp IC (Figure 4).

The operation of the circuit is described under three conditions, case 0,1 and 2, respectively (as mentioned in section 2.4). Case 0 mimics

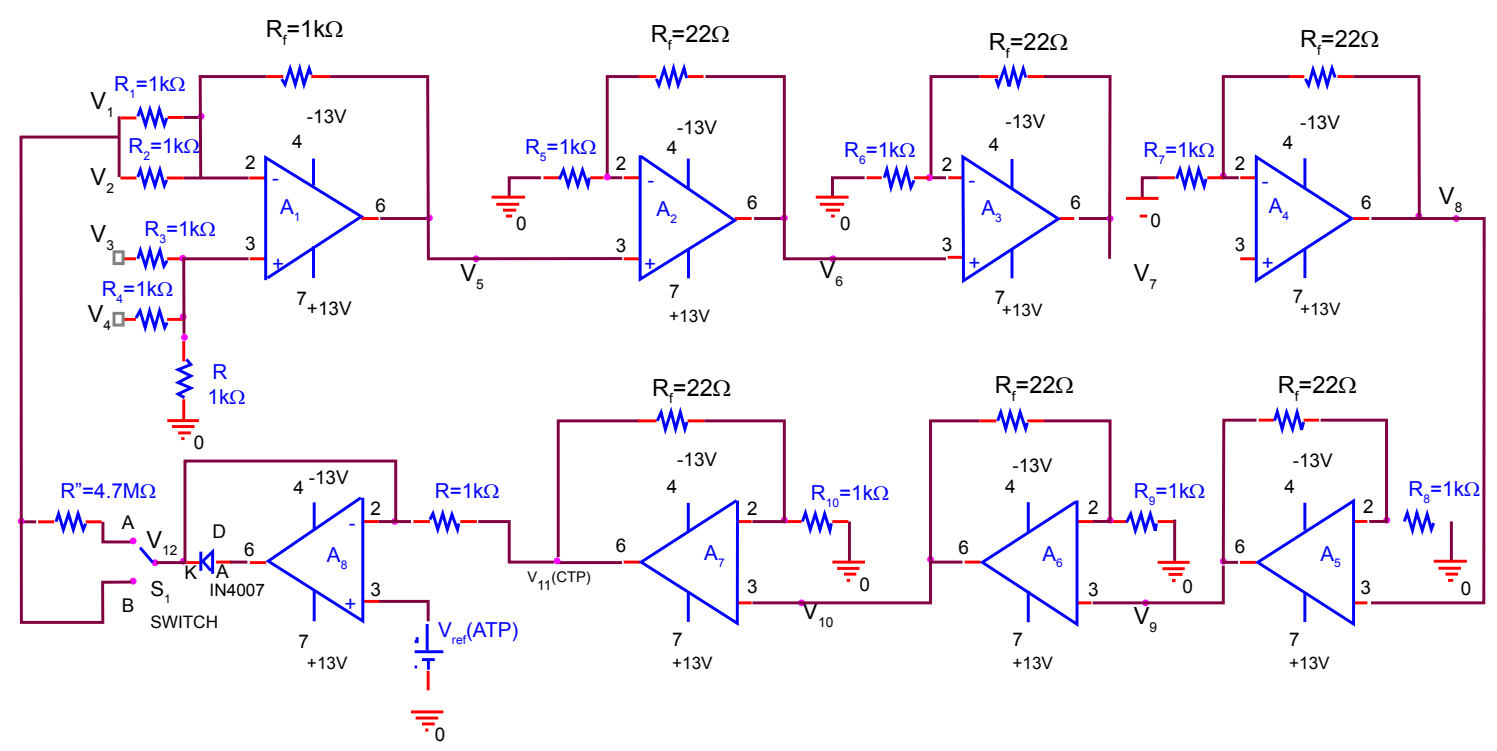

Figure 4: The biomimetic feedback circuit design. 


\begin{tabular}{|c|c|c|c|}
\hline Output & Case 0 $(\mathrm{V})$ & Case 1 $(\mathrm{V})$ & Case 2 $(\mathrm{V})$ \\
\hline V5 & 0.750 & -0.842 & 0.248 \\
\hline V6 & 0.764 & -0.863 & 0.253 \\
\hline V7 & 0.784 & -0.883 & 0.257 \\
\hline V8 & 0.791 & -0.904 & 0.262 \\
\hline V9 & 0.820 & -0.924 & 0.267 \\
\hline V10 & 0.830 & -0.944 & 0.274 \\
\hline V11 & 0.852 & -0.966 & 0.280 \\
\hline
\end{tabular}

Table 1: The output voltage from op-amps of the tested electronic feedback circuit is given for each case.

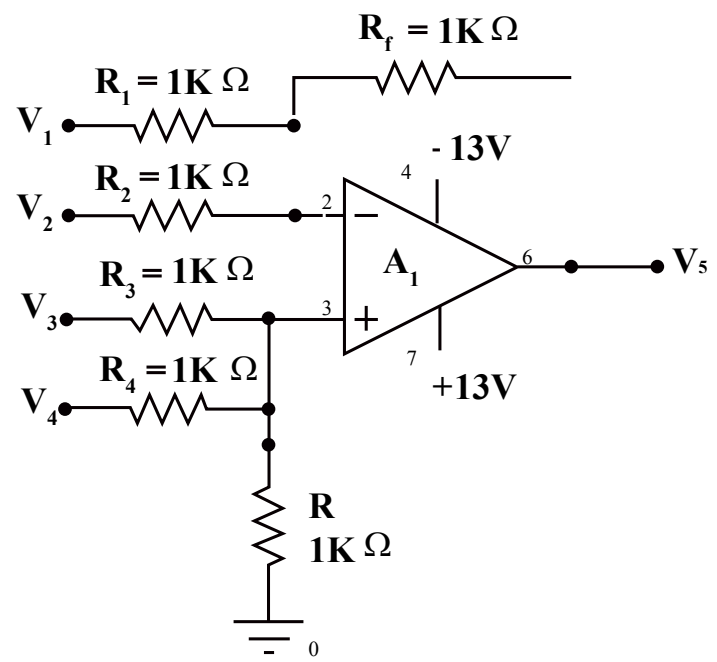

Figure 5: The pacemaker circuit (ATCase).

\begin{tabular}{|c|c|c|c|c|c|c|c|c|}
\hline \multicolumn{3}{|c|}{ Enzyme } & \multicolumn{3}{c|}{ CTP } & \multicolumn{3}{c|}{ ATP } \\
\hline $\mathrm{V}_{3}(\mathrm{~V})$ & $\mathrm{V}_{4}(\mathrm{~V})$ & $\mathrm{V}_{5}(\mathrm{~V})$ & $\mathrm{V}_{3}(\mathrm{~V})$ & $\mathrm{V}_{4}(\mathrm{~V})$ & $\mathrm{V}_{5}(\mathrm{~V})$ & $\mathrm{V}_{3}(\mathrm{~V})$ & $\mathrm{V}_{4}(\mathrm{~V})$ & $\mathrm{V}_{5}(\mathrm{~V})$ \\
\hline 0.00 & 0.00 & 0.00 & 0.00 & 0.00 & 0.00 & 0.00 & 0.00 & 0.00 \\
\hline 1.01 & 1.01 & 2.03 & 1.03 & 1.03 & 1.17 & 1.06 & 1.06 & 2.48 \\
\hline 2.03 & 2.03 & 4.06 & 2.12 & 2.12 & 2.41 & 2.18 & 2.18 & 5.11 \\
\hline 3.00 & 3.00 & 6.01 & 3.17 & 3.17 & 3.61 & 3.13 & 3.13 & 7.33 \\
\hline 4.22 & 4.22 & 8.45 & 4.16 & 4.16 & 4.72 & 4.15 & 4.15 & 9.70 \\
\hline 5.06 & 5.06 & 10.17 & 5.20 & 5.20 & 6.00 & 5.00 & 5.00 & 10.9 \\
\hline 5.64 & 5.64 & 11.33 & 6.10 & 6.10 & 6.91 & 6.16 & 6.16 & 11.9 \\
\hline 5.77 & 5.77 & 11.53 & 7.01 & 7.01 & 7.95 & 7.29 & 7.29 & 11.9 \\
\hline 5.93 & 5.93 & 11.68 & 8.15 & 8.15 & 9.24 & 8.56 & 8.56 & 11.9 \\
\hline 7.03 & 7.03 & 11.69 & 9.00 & 9.00 & 10.19 & 9.54 & 9.54 & 11.9 \\
\hline 9.72 & 9.72 & 11.69 & 9.64 & 9.64 & 10.85 & 10.82 & 10.82 & 11.9 \\
\hline 10.2 & 10.2 & 11.69 & 10.34 & 10.34 & 10.85 & 11.21 & 11.21 & 11.9 \\
\hline
\end{tabular}

Table 2: The input $\left(V_{3}+V_{4}\right)$ and the output voltage $\left(V_{5}\right)$ of $A_{1}$ with different $R_{3}$ and $R_{4}$ of the pacemaker circuit.

the enzymes in normal condition. The substrates, carbamoyl phosphate and aspartate were mimicked by the input voltage $(0.378 \mathrm{~V})$ to the noninverting terminal $\left(\mathrm{V}_{3}\right.$ and $\left.\mathrm{V}_{4}\right)$. The final output, $0.852 \mathrm{~V}(\mathrm{~V} 11)$ was considered as the end product (CTP). Case 1 mimics the situation in which CTP (V11) is produced more $(0.852 \mathrm{~V})$ than the external voltage $\mathrm{V}_{\text {ref }}(0.800 \mathrm{~V})$, where $\mathrm{V}_{\text {ref }}$ mimics the heterotropic activator (ATP). As a result, all the corresponding outputs of op-amps were negative. This indicates that the enzyme ATCase is inhibited by CTP, which shifts the equilibrium towards the $\mathrm{T}$ state, decreasing the net enzyme activity. In case 2, ATP $\left(\mathrm{V}_{\text {ref }}\right)$ is $0.900 \mathrm{~V}$ and hence all the corresponding outputs of op-amps were positive. This indicates a steep rise in activity. This mimics the positive cooperativity of ATCase. The outputs of op-amps observed under different conditions are given in Table 1.

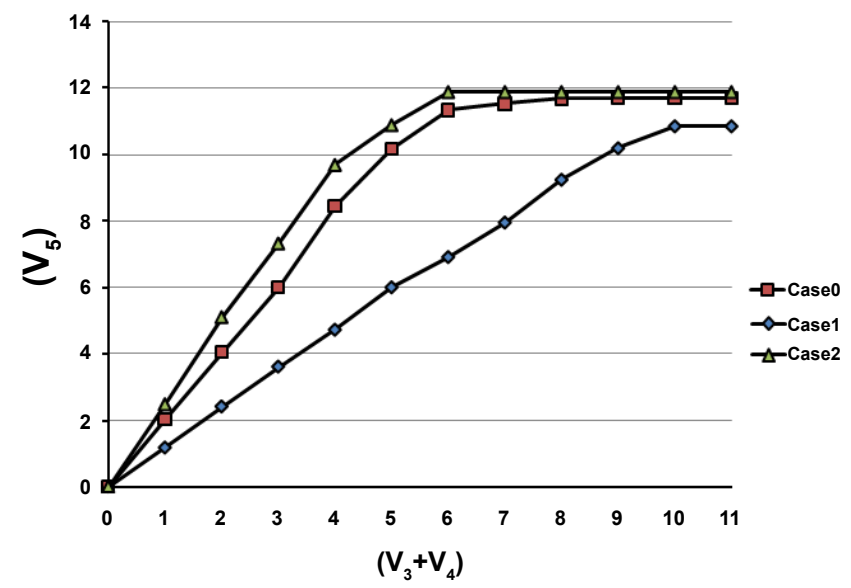

Figure 6: The input (abscissa) and the output voltage (ordinate) of A1 with different R3 and R4 of the pacemaker circuit shows sigmoidal plot.

The pacemaker circuit is modeled with $\mathrm{R}_{3} \& \mathrm{R}_{4}$ as $1 \mathrm{~K} \Omega$ is depicted in Figure 5. The input voltages $\left(\mathrm{V}_{1}=\mathrm{V}_{2}=0\right)$ and the corresponding $\mathrm{V}_{3} \& \mathrm{~V}_{4}$ is showed in Table 2. The allosteric inhibitor, CTP was mimicked by $\mathrm{R}_{3}$ $\& \mathrm{R}_{4}$ as $3.3 \mathrm{~K} \Omega$, whereas the heterotropic activator, ATP was mimicked by $\mathrm{R}_{3} \& \mathrm{R}_{4}$ as $560 \Omega$. The output $\left(\mathrm{V}_{5}\right)$ of the modeled pacemaker circuit is showed in Table 2 for the three sets of $R_{3} \& R_{4}$ values. The pacemaker enzyme ATCase does not conform to Michaelis-Menton kinetics, have multiple active sites. These active sites display cooperativity, as evidenced by a sigmoidal dependence of reaction velocity on substrate concentration [14].

Our findings on the output of pacemaker circuit showed strikingly a sigmoidal plot based on the input voltage (Figure 6). The generated sigmoidal curve for the allosteric enzyme can be considered as a mixture of two Michaelis-Menten enzymes, one with a high value of $K_{M}$ that corresponds to the T state (ATP) and another with a low value of $K_{M}$ that corresponds to the R state (CTP) [14]. Ironically, the case was upside down with the mimic circuit, an indirect proportion between $K_{M}$ and $\mathrm{R}$ was observed. A higher resistance $\left(\mathrm{R}_{3} \& \mathrm{R}_{4}=3.3 \mathrm{~K} \Omega\right)$ corresponds to CTP and lower resistance $\left(\mathrm{R}_{3} \& \mathrm{R}_{4}=560 \Omega\right)$ corresponds to ATP.

\section{Conclusion}

The designed circuit can be used to model the bioprocess and its regulation on metabolite production. It can also be used to analyze metabolic fluxes and their control. The analysis does not require knowledge of metabolite concentration or details of the enzyme kinetics of the system. The assumption is made that the given input voltage undergoes amplification at each stage. The output of each stage from non-inverting amplifier can be tapped out for the analysis. Once it reaches the desired threshold, feedback inhibition occurs through precision clamp (precision threshold detector). Then the pacemaker circuit functions as an adder/subtractor to regulate the output. The biomolecular mimetic approach can also be used as a central controlling circuitry in various industrial applications due to the difference in voltage tapings [25]. The pacemaker circuit may act as a control valve to alter the simulated flux of small molecules through the metabolic pathway. The designed electronic circuit will develop a new level of understanding of the metabolic complexity in the cell.

\section{Acknowledgement}

The authors show their gratitude to the Director, Manipal Institute of Technology, Manipal University. They also extend their gratitude to their department heads, 
Citation: Vinoth R, Balaji S (2012) Biomolecular Mimic Circuit for an Allosterically Regulated Enzyme of Pyrimidine Biosynthetic Pathway. J Biosens Bioelectron 3:117. doi:10.4172/2155-6210.1000117

Page 5 of 5

Dr. Kumara Shama, Department of ECE and Dr. V. Ramachandra Murthy, Dept. of Biotechnology, respectively. The authors like to thank the students Mr. N. B. Prashanth and Mr. M. Sai Pranav for their support in preparing the diagram of the designed circuit. The authors are also thankful to Mr. Ravi Shriyan and Mr. H. Krishnananda Pai for providing the necessary equipments.

\section{References}

1. Haynie DT (2008) Biological thermodynamics. (2ndedn), Cambridge University Press, Cambridge, New York.

2. Murray RK, Granner DK, Mayes PA, Rodwell VW (2003) Harper's Illustrated Biochemistry. (26thedn), McGraw-Hill Companies, Inc.

3. Hervé G (1989) Allosteric Enzymes. CRC Press, Boca Raton.

4. Lipscomb WN (1994) Aspartate transcarbamylase from Escherichia coli: activity and regulation. Adv Enzymol Relat Areas Mol Biol 68: 67-151.

5. Jones ME, Spector L, Lipmann F (1955) Carbamyl phosphate, the carbamyl donor in enzymatic citrulline synthesis. J Am Chem Soc, 77: 819-820.

6. Zanotti JM, HervÃG, Bellissent-Funel MC (2006) Picosecond dynamics of $\mathrm{T}$ and $\mathrm{R}$ forms of aspartate transcarbamylase: a neutron scattering study. Biochim Biophys Acta 1764: 1527-1535.

7. Stieglitz KA, Dusinberre KJ, Cardia JP, Tsuruta H, Kantrowitz ER (2005) Structure of the E.coli aspartate transcarbamoylase trapped in the middle of the catalytic cycle. J Mol Biol 352: 478-486.

8. Herve G, Moody MF, Tauc P, Vachette P, Jones PT (1985) Quaternary structure changes in aspartate transcarbamylase studied by X-ray solution scattering. Signal transmission following effector binding. J Mol Biol 185: 189-199.

9. Gerhart JC, Pardee AB (1963) The effect of the feedback inhibitor CTP, on subunit interactions in aspartate transcarbamylase. Cold Spring Harbor Symp. Quant Biol 28: 491-496.

10. Gerhart JC, Schachman HK (1968) Allosteric interactions in aspartate transcarbamylase II. Evidence for different conformational states of the protein in the presence and absence of specific ligands. Biochemistry 7: 538-552.

11. Wild JR, Loughrey-Chen SJ, Corder TS (1989) In the presence of CTP, UTP becomes an allosteric inhibitor of aspartate transcarbamoylase. Proc Natl Acad Sci U S A 86: 46-50.
12. Nelson DL, Cox MM (2004) Lehninger Principles of Biochemistry. (4thedn), WH Freeman, New York

13. Stieglitz K, Stec B, Baker DP, Kantrowitz ER (2004) Monitoring the transition from the $T$ to the $R$ state in E.coli aspartate transcarbamoylase by $\mathrm{x}$-ray crystallography: crystal structures of the E50A mutant enzyme in four distinct allosteric states. J Mol Biol 341: 853-868.

14. Berg JM, Tymoczko JL, Stryer L (2002) Biochemistry (5thedn), WH Freeman New York.

15. Coughlin RF, Driscoll FF (2001) Operational amplifiers and linear integrated circuits. (6thedn), Pearson Education, India.

16. Jain GC, Jain M (1981) Practical semiconductors data manual (Vol 2), Buisness promotion publications, Delhi, India.

17. Monod J, Wyman J, Changeux JP (1965) On the nature of allosteric transitions: a plausible model. J Mol Biol 12: 88-118.

18. Koshland DE Jr, NÃmethy G, Filmer D (1966) Comparison of experimental binding data and theoretical models in proteins containing subunits Biochemistry 5: 365-385.

19. Michaelis L, Menten M L (1913) Kinetik der Invertinwirkung. Biochem Z 49 333-369.

20. Choudhury DR, Jain SB (200) Linear Integrated Circuits. (3rdedn), New Age International Publishers, India.

21. Lineweaver $H$, Burk $D$ (1934) The determination of enzyme dissociation constants. Journal of the American Chemical Society 56: 658-666.

22. Sedra AS, Smith KC (2002) Microelectronic circuits. (4thedn), Oxford University Press, Printed in India at Gopson papers Ltd., Noida, India.

23. Nagrath IJ (2004) Electronics-Analog and Digital. Prentice-Hall, New Delhi, India.

24. Millman J, Halkias CC (1991) Integrated Electronics: Analog and digital circuits and systems. Tata McGraw-Hill Edn, India .

25. Balaji S, Lakshminarayanan S (2004) Conceptual comparison of metabolic pathways with electronic circuits. Journal of Bionics Engineering 1: 175-182. 